England, against 6,069 in Manchester and 8,711 in Glasgow.

In the first five years of life we have seen that 33,130 die in Glasgow, as compared with $32, \mathrm{ro}_{4}$ out of an equal number of male births in Manchester.

The number of male lives saved in Glasgow, owing to the lower mortality in the first year of life, is sufficiently large to maintain a large number living, as compared with Manchester, till the third year of life, although the mortality of Glasgow is greater than that of Manchester in the second year. Pursuing the analysis, we find that of the 67,896 males alive in Manchester at five years of age, 4,820 die in the next ten years, and at the same rate of decrease the 66,870 living at five years of age in Glasgow should lose by death 4,748 before reaching the age of 15 , and 62,122 instead of 61,779 should then survive. But 5,09I deaths take place in Glasgow, or an excess of 343 , representing the number of male lives lost in access to Glasgow in the period 5.15 as compared with Manchester.

At the latter age, viz., I 5 years, school life has for most children ceased. Inherited diseasedisease incidental to child-life, especially in a city population, and that worse danger to child-life, to which so many of our city children are exposed, in the form of parental neglect-have each contributed their share of the 38,221 deaths which occur before the survivors of our 100,000 male births have reached their $15^{\text {th }}$ year. That is, the risks of childhood and school-age have been overcome, how do the survivors fare in the period of adolescence? $6 \mathrm{I}, 779$ have survived to complete their $15^{\text {th }}$ year in Glasgow, 63,076 in Manchester. In Glasgow 57,288 of that number survive to complete their 25th year, in Manchester 59,645-that is, out of a large number beginning adolescence in Manchester there are fewer deaths. The deaths in Manchester were 3,431, in Glasgow $4,49 \mathrm{I}$; but had the Glasgow deaths occurred at the same rate as in Manchester, we should have had 58,434 surviving to complete their $25^{\text {th }}$ year instead of 57,288 . Or, instead of 4,491 deaths, should only have had 3,345 , and 1,146 male lives would have been saved to the community in the period.

Thereafter the probability of living is greater in Glasgow, but the number of lives saved in the earlier years in Manchester maintains a larger number surviving till the age of 40 is reached.

Advantage has been taken of the appended chart to introduce contrast curves, showing the expectation of life, derived from the rates of mortality, which ootained during several years of the third decade of this century.

These are derived from a life table constructed in 1829 by Mr. Duncan, on the basis of the mortality experience of Glasgow for the years $182 \mathrm{I}-7$.
The contrasts presented by these curves sufficiently indicate the changes which have taken place, in the expectation of life, during the intervening years. There is at birth now an increased expectation of life, for each sex, of fully a year. The greatest probable after lifetime by the old rate was $44^{\circ} 4^{6}$ years for males, and $47^{\circ} 35$ years for females, on the completion of the sixth and fifth year of life respectively. At six years of age males have now a probable after lifetime of $46 \cdot 7^{2}$ years, while the maximum expectation is, as we have seen, $47^{\circ} 3$ years, at four years of age. That is an increase of 2.27 years at the age when the probable after lifetime is greatest. For females the change has been less marked. At five years of age their expectation of life now is $48 \cdot 27$ years, as against 4735 years then, and the maximum at four years now is 48.29 years, which exceeds by nearly one year the maximum formerly attained.

\section{MEASURES FOR THE PREVENTION OF TUBERCULOUS INFECTION BY MILK AND MEAT.}

By H. Scurfield, M.D., D.P.H.

THe following paper is the result of a discussion on the subject by the Northern Branch of Medical Officers of Health, and is written in the belief that eating the meat of animals affected with tuberculosis is an insignificant factor in the causation of the disease in man ; that the milk of such animals is a greater source of danger, but that the proposal to destroy all such animals is impracticable. At the same time, the necessity for reform in our disgusting system of private slaughterhouses, and for a more strict control of the milk during the whole of its journey from the cow to the consumer, will probably be acknowledged by all. The extent of the danger from the milk and meat was reviewed by Professor Bang, in a paper read at the Congress of Hygiene and Demography, held in London in I891. Since that time Professor Baug has seen no reason to alter his opinion, and I append accounts of experiments, \&c., recorded by him on that occasion.

\section{DANGer from THE Milk.}

With the milk must be classed all its products, it having been shown by Galtier, Heim, Bang, and Gasperini, that tubercle bacilli may live for many weeks in butter and cheese. When the udder of the cow is affected, the milk usually contains numerous bacilli, and is very dangerous; the danger being increased by the fact that the milk is generally normal in appearance for the first few weeks of the affection. In the Copenhagen abattoir the udder is found to be affected in about one per cent. of cattle affected with tuberculosis. 
In cases where the udder is healthy, Bang has made three series of experiments :-

I. The milk of twenty-eight tuberculous cows was inoculated into rabbits, and the milk of two of the cows proved virulent.

2. The milk of twenty-eight tuberculous cows was inoculated into guinea-pigs, and the milk of four proved virulent.

3. The milk of fourteen extremely tuberculous cows was inoculated into guinea-pigs, and the milk of three proved virulent.

In this last series a larger quantity of milk was used.

The total result is that the milk of nine cows out of sixty-three proved virulent, nearly all of these cows being tuberculous in a high degree, some having tuberculous disease of the udder which had not been diagnosable during life, and others having acute miliary tuberculosis in several organs.

These experiments show that though the milk of tuberculous cows is not dangerous in the majority of cases, yet that it is so in some cases; hence one must always view it with suspicion, and take prophylactic measures accordingly.

What prophylactic measures can be taken?

x. All the milk used for human consumption, either as milk, butter, cheese, \&c., may be exposed to a temperature of 85 degs. C. before use.

2. All the cows used for supplying milk may be inspected once a fortnight-such frequency being necessary owing to the rapid development of tuberculosis of the udder-by veterinary surgeons, any cows found by examination to be suffering from tuberculosis to be rejected for use as milk suppliers.

To show that these measures are not absolutely Utopian, I may mention that the Copenhagen Milk Supply Company, organised by Mr. G. Busck, of that city, carries out the second of these measures with regard to all its milk, and the first of these measures with regard to the milk sold by them as "Infants' Milk"; and at the same time pays five per cent. to the shareholders, and the best price in the market to the farmers who supply the milk.

Danger from the Meat.

The muscle itself very rarely contains tubercular nodules, but even when it does not, it may contain the bacilli. In the experiments of Chauveau, Arloing, Peuch, Galtier, Nocard, and Kastner, the muscle juice of seventy-three tuberculous cows was inoculated into guinea pigs and rabbits, and the muscle juice of ten of the cows proved virulent sometimes only one of many animals inoculated with the same cow's juice becoming infected. Nocard found that if he injected cultures very rich in bacilli into the veins of rabbits, the muscle juice of the rabbits remained virulent for five days, but not after five days.

The rarity of the tubarcular nodules in muscle and this last experiment seem to point to the fact that muscle is hostile to the bacilli, and will only remain virulent if the blood is constantly receiving injections of bacilli ; and in Bang's opinion it will only be in cases of acute miliary tuberculosis that the number of bacilli introduced into the bloodvessels will be considerable.

Bang inoculated to to 18 c.c. of the blood of twenty highly tuberculous cows into the peritoneal cavity of rabbits and guinea-pigs, and the blood of two of the twenty cows proved virulent; while among the negative cases were several of acute miliary tuberculosis.

In considering the import of these experiments, it must be remembered that the inoculation of the raw material and the swallowing of the cooked material into the acid stomach are two very different matters.

Galtier draws this conclusion from his experiments :-

It would appear that the eating of the meat of tuberculous animals, except the organs affected, would hardly ever be dangerous. I believe in consequence, until further experience, that it has been wistly decided that it is not necessary to seize the flesh of animals affected by tuberculosis when the disease is little advanced, and that it is sufficient to seize the affected organs.

Bang says :-

I think that the seizure of the meat of every tuberculous animal is too severe a measure. As long as the tuberculosis is truly localized, the meat can offer no danger. When the malady is generalized, the consumption of the meat may be dangerous, It is therefore the restricted seizure that one must adopt, or rather continue, as that is the plan most generally in use.

\section{Prophylactic Measures.}

r. Any individual may protect himself by never eating undercooked meat, Bang having shown that heating to $85^{\circ} \mathrm{C}$. kills the bacili, and heating for five minutes to $70^{\circ} \mathrm{C}$, and sometimes to $60^{\circ} \mathrm{C}$., so enfeebles them that they are unable to produce infection by the digestive tract.

2. The universal establishment of public abattoirs and the compulsory use of them by the butchers of the district which owns the abattoir.

Some such regulations as the following would be necessary for the working of the abattoir:-

The examination by veterinary surgeons at the abattoir, both of all meat slaughtered there, and of all meat imported into the district, but not slaughtered there.

The stamping of all meat passed by the veterinary surgeons; one form of stamp being used for meat slaughtered at the abattoir, and another for meat simply examined there, the examination in the latter case being incomplete, owing to the absence of the offal and organs.

With regard to tuberculosis, the veterinary surgeons would act in some such fashion as the following :-

$x$. In case of localized tuberculosis $(e . g .$, one or two nodules in one organ, with affection of the 
corresponding lymphatic glands), the meat, if of good quality, would be passed, the organ and glands being destroyed.

2. If the tuberculosis were found in several organs, or in a position which it could only have reached by the blood current, such as the kidney, the meat, if in good condition, would be subjected to prolonged boiling in the abattoir and sold at a cheap rate, as is done in Berlin and other continental towns,

3. If the tuberculosis were advanced, and marked signs of wasting of the animals present, the meat would be destroyed altogether.

It must not be forgotten that tuberculosis is found in animals which would not come under inspection at the abattoir, such as poultry, game, pigeons, rabbits, etc.; but I fancy the flesh of these is seldom eaten undercooked, as is the case with beef.

In conclusion, the use of tuberculin, which has proved an absolutely reliable diagnostic test of the presence of tuberculosis in cattle, has revealed the fact that tuberculosis of some degree is astonishingly common among cattle in some countries. In Denmark a large proportion of the cattle are affected with tuberculosis in some degree; and until in England we have some idea of its prevalence, either by the use of tuberculin or rigorous examination in abattoirs, it is impossible to advocate such a heroic measure as the destruction of all cattle affected by it.

At the present time it is impracticable, according to Bang, to reject the milk of all cows which give a reaction with tuberculin in Denmark.

\section{Action of the Danish Government.}

The Danish Government has voted a sum of money to enable farmers who wish it, to have their herds tested with tuberculin free of charge.

Out of $x 1,619$ cattle of all ages on 474 farms, tested in this way, 4,512 or 38.9 per cent. gave a reaction. Of course, it would be wrong to suggest that this percentage represents the prevalence of the disease throughout the country, because naturally the farmers who had the tuberculin applied would be those whose herds were most seriously affected by tuberculosis, and also it is known that many of the herds are quite free from the disease.

Professor Bang has originated a scheme for the gradual stamping out of tuberculosis in cattle by testing the herd with tuberculin, and isolating those animals affected from those not affected.

A herd on which this plan is tried is tested every six months with tuberculin and divided into two divisions, those which give a reaction and those which do not. The two divisions are kept separate and have different attendants. Animals with advanced tubercle belonging to the tuberculous division are got rid of. Calves born to the tuberculous division are at once removed to isolated boxes and fed on boiled milk; they are tested with tuberculin during the first few weeks of life, and if they give no reaction are then removed to the non-tuberculous division and continue to be fed with boiled milk.

Dr. Bang has kindly supplied me with the following particulars as to the results of the working of his scheme on one herd.

In May, 1892 , the herd in question, consisting of 208 animals, was first tested with tuberculin; 80 per cent. of the cows, 40 per cent. of the bulls, and 40 per cent. of the heifers and calves reacted and constituted the tuberculous division.

In October, 1892 , the non-tuberculous division consisted of 70 animals; 7 of these reacted and were removed to the tuberculous division.

In May, 1893, the non-tuberculous division consisted of ro3; ro reacted and were removed.

In October, 1893 , the non-tuberculous division consisted of 107 ; I reacted and was removed.

In May, 1894 , the non-tuberculous division consisted of $12 z ; 2$ reacted and were removed.

In October, $x 894$, the non-tuberculous division consisted of II9; I of these was suspicious.

Not one of the calves born to the tuberculous division has become tuberculous during these two and a-half years.

In view of the prevalence of tuberculosis among cattle in Denmark, some comparison between the human death rates from that cause in Denmark and England may be interesting.

I have used the Registrar-General's Reports for 1889 , $189 \circ$, and 1891 , and the statistics given in the book on Denmark, published by the Danish Government in $189 \mathrm{r}$; and as there are no accurate reports from rural districts in Denmark, I have compared Copenbagen and the Danish towns with London.

In London, in $189 x$, there were 89,122 deaths, and of these 11,854 , or 13.3 per cent, were due to tuberculosis; also there were 38,4 or deaths under five years of age, of which 3,028 , or 9 per cent. were due to tuberculosis. In London, in 1889 , there were 76,026 deaths, of which 11,168 were due to tuberculosis, or $14^{.6}$ per cent.; and 30,469 deaths under five, of which 2,923 , or 9.59 per cent., were due to tuberculosis. In London, in $x 890$, there were 87,689 deaths, of which 12,306 , or 14 per cent., were due to tuberculosis; and 35,494 deaths under five, of which 3,206 , or 9 per cent., were due to tuberculosis.

In Copenhagen and the Danish towns, during the years 188 -1889, inclusive, there were 69,797 . deaths, of which $9,29^{2}$, or $x^{*} 3$ per cent., were due to tuberculosis; and 28,910 deaths under five years of age, of which 918 , or $3^{\prime}$ per cent., were due to tuberculosis. In Copenhagen and the Danish towns, during the years $1880-1889$, there were 55,733 deaths under five years of age from all causes, and of these $x, 985$, or 3.5 per cent., were due to tuberculosis.

It will be seen that the death rate at all ages 
from tuberculosis bears a similar ratio to the total death rate in London and in the Danish towns, while tuberculosis is accountable for a far greater proportion of the deaths under five in London than it is in Copenhagen and the Danish towns. This comparison of the death rates under five does not suggest that milk from tuberculous cows is a more potent factor in the causation of infant tuberculosis in the Danish towns than it is in London. Since writing the above, I see that Professor McFadyean estimates that 20 per cent. of the adult cattle in Great Britain are affected by tuberculosis.

\section{THE PATHOLOGY OF VACCINIA.}

By S. Monckton Copeman, M.A., M.D. (Cantab.), M.R.C.P., Lecturer on Hygiene and Public Health, Westminster Hospital Medical School.

International Congress of Hygiene, Budapest, Sept., 1894.)

THE subject which, on the present occasion I propose briefly to discuss is the Pathology of Vaccinia, for the reason that this subject is one in which I have always felt the greatest interest, and also because having at intervals for the last four or five years, as occasion served, been actively engaged in research work in connection with this problem I have for this reason also endeavoured as far as possible to make myself acquainted with the results attained by other workers in the same field.

I must confess, however, to considerable doubt as to the possibility of presenting to you, especially in the limited time at my disposal, anything like a complete resumé of the vast amount of experimental work which has been carried on with the object of dispelling the obscurity in which the Pathology of Vaccinia has for so long been shrouded.

Indeed, so impossible do I consider such a task, that in the present paper $I$ think it will be well practically, to confine myself almost entirely to a consideration of the work bearing on this problem which has been done within the last few years.

The results which have thus far been obtained by various observers, although in my opinion tending for the most part in the same direction, undoubtedly show discrepancies which at first sight it appears difficult to harmonise; but I shall endeavour to show, in the first place, in what these discrepancies consist, and secondly, how far they can be reconciled.

From the time that vaccination was first intro. duced as a prophylactic against small-pox, the main dispute with reference to the pathology of the disease has centred round the term variolæ vaccinæ given to it in the first instance by Jenner, who undoubtedly looked upon it as "small-pox of the cow." The question for consideration is, then, whether vaccinia is or is not one with small-pox, or whether it is an absolutely distinct disease.
This problem has been attacked from two separate points :-

Ist. Microscopic Pathology, including Bacteriology; and

2nd. Experimental work, having for its object the production-if that be possible - in the bovine animal, by inoculating it with small-pox lymph, o: a disease indistinguishable both in its local and in its general effects by any means at our command from true vaccinia.

But first a word or two with reference to the prophylactic effect of vaccination. Whatever may be their views as to the desirability of the practice of vaccination, and more particularly of compulsory vaccination, I suppose that there are very few scientists at the present day who would deny that vaccination affords, for a time, at any rate, protection against invasion of the system by small-pox.

If this be so, the fact affords strong presumption of, at the least, an intimate relationship between these two diseases, since we have but little reason to suppose that protection can be afforded against any given disease by the inoculation of the living virus of another, and essentially distinct, malady. I am, of course, aware that from time to time apparent exceptions to such statement have been brought forward, but to these it is impossible for me to do more than refer on the present occasion.

VARIOLATION OF BOVINES.

Taking into consideration, in the first place, the experimental work, having for its object the variolation of the bovine animal, it is obvious that the literature of the subject is so extensive that it is impossible here even to mention the names of all those who have engaged in this branch of the subject. What I believe to be a fairly complete list, however, will be found in a paper which I have recently published in the Journal of Pathology and Bacteriology.

It is a noteworthy fact that of the various observers mentioned in that list, everyone, with the exception of Chauveau and his colleagues of the Lyons Commission, claims to have obtained positive results as regards the production of typical vaccinia, after one or more removes, as the result of variolation of the cow or calf.

In many cases, it is true, a large number of experiments are stated to have been abortive, especially among the older observers, who made use for the most part of heifers or milch cows. Subsequent experience has shown, however, that success is much more likely to be obtained, if, instead of heifers or cows, the calf be used. On this account, perhaps, Chauveau's want of success may be in part explained.

With reference to recent experiments on variolation of the calf, it is worthy of note also that different observers have obtained results differing considerably in certain instances in the immediate effect produced. 